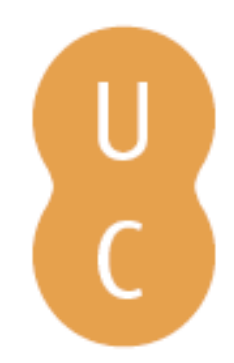

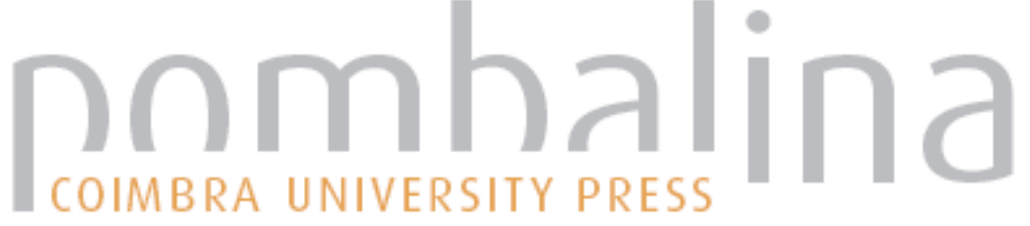

\section{A matemática no melhor mundo possível}

Autor(es): $\quad$ Tromba, A. J.

Publicado por: Imprensa da Universidade de Coimbra; Gradiva

URL

persistente: URI:http://hdl.handle.net/10316.2/32626

DOI: $\quad$ DOI:http://dx.doi.org/10.14195/978-989-26-0485-5_16

Accessed : $\quad$ 26-Apr-2023 04:03:45

A navegação consulta e descarregamento dos títulos inseridos nas Bibliotecas Digitais UC Digitalis, UC Pombalina e UC Impactum, pressupõem a aceitação plena e sem reservas dos Termos e Condições de Uso destas Bibliotecas Digitais, disponíveis em https://digitalis.uc.pt/pt-pt/termos.

Conforme exposto nos referidos Termos e Condições de Uso, o descarregamento de títulos de acesso restrito requer uma licença válida de autorização devendo o utilizador aceder ao(s) documento(s) a partir de um endereço de IP da instituição detentora da supramencionada licença.

Ao utilizador é apenas permitido o descarregamento para uso pessoal, pelo que o emprego do(s) título(s) descarregado(s) para outro fim, designadamente comercial, carece de autorização do respetivo autor ou editor da obra.

Na medida em que todas as obras da UC Digitalis se encontram protegidas pelo Código do Direito de Autor e Direitos Conexos e demais legislação aplicável, toda a cópia, parcial ou total, deste documento, nos casos em que é legalmente admitida, deverá conter ou fazer-se acompanhar por este aviso.

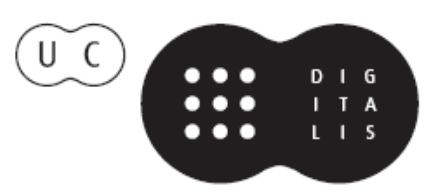


(Página deixada propositadamente em branco) 
MARIA PAULA SERRA DE OLIVEIRA

Coordenadora

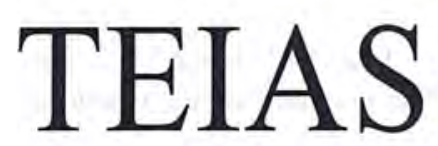

MATEMÁTICAS

Frentes na Ciência e na Sociedade 
(C) Gradiva - Publicações, L. da / Imprensa da Universidade de Coimbra, 2004 Coordenação editorial: Maria Paula Serra de Oliveira

Tradução: Artur Soares Alves

Carlota Isabel Leitão Pires Simões

Francisco José Craveiro de Carvalho

João Filipe Cortez Rodrigues Queiró

José Miguel Dordio Martinho de Almeida Urbano

Lia Sandra dos Santos

Mário da Silva Rosa

Paulo Eduardo Aragão Aleixo Neves de Oliveira

Revisão do texto: Isabel Pedrome

Capa: António Barros [Imprensa da Universidade. Coimbra], com imagem de

E. M. de Melo e Castro, "Fract 010 explod MC", Dezembro de 2003

[Fractal original gerado no Fractint com tratamento no Photoshop 7.0]

Infografia: Estúdios Estímulus [design]

Paginação: António Resende e Victor Hugo Fernandes

Impressão e acabamento: G.C. - Gráfica de Coimbra, L. da

Reservados os direitos para Portugal por:

Gradiva - Publicações, L. ${ }^{\text {da }}$ e Imprensa da Universidade de Coimbra

Gradiva - Publicações, L. ${ }^{d a}$

Rua Almeida e Sousa, 21, r/c, esq. • 1399-041 Lisboa

Telefs. $213974067 / 8 \cdot 213971357 \cdot 213953470$

Fax $213953471 \cdot$ Email: gradiva@ip.pt

URL: http://www.gradiva.pt

Imprensa da Universidade de Coimbra

Rua Antero de Quental, 195 • 3000-033 Coimbra

Telefs. 351239853110

Fax 3512398531 19 e-mail: fjrpress@ci.uc.pt

URL: http://www.imp.uc.pt

ISBN: 972-662-970-5

1." edição: Maio de 2004

Depósito legal n. ${ }^{\circ} 210431 / 04$

OBRA PUBLICADA COM O PATROCÍNIO DE:

CENTRO DE MATEMÁTICA DA UNIVERSIDADE DE COIMBRA DEPARTAMENTO DE MATEMÁTICA DA UNIVERSIDADE DE COIMBRA

FCT Fundação para a Ciência e a Tecnologia

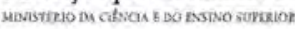




\section{A. J. Tromba}

Universidade da Califórnia

Santa Cruz, EUA

\section{A matemática no melhor mundo possível}

De acordo com os estudos de ADN mitocondrial, a nossa espécie terá começado há uns 200000 anos. Contudo, alguns estudiosos crêem que a verdadeira consciência começou muito mais tarde.

Quando a consciência de si e do mundo se instalaram, o planeta deve ter sido um lugar terrivelmente assustador e inexplicável. $\mathrm{O}$ homem estava cercado por acontecimentos muito para além da sua compreensão e do seu controlo; de tremores de terra, cheias, tufões e secas a cometas e eclipses solares e lunares.

Para além de ter dificuldade em perceber estes acontecimentos naturais terriveis, muito provavelmente a humanidade tinha dificuldade em tomar conta dos seus haveres, da passagem do tempo ou mesmo do planeamento do futuro. Sabemos que os processos de contagem começaram há pelo menos 35000 anos. Marcas em fragmentos ósseos indicam que, mesmo nessa altura, se podem encontrar rudimentos do conceito de base aritmética (por exemplo, as bases 5 e 10).

A história dos números, isto é, o desenvolvimento do sistema aritmético actual, notação aritmética e operações, é fascinante. É uma

1 Tradução de F. J. Craveiro de Carvalho, professor do Departamento de Matemática, Universidade de Coimbra. 
história que põe a claro a dificuldade que muitas grandes civilizações não foram capazes de vencer para obter um sistema de cálculo eficaz. Mas os números, em si e por si, não são matemática. A palavra grega mathema significa saber, conhecimento, compreensão, percepção - sugerindo que a história da matemática começou com tentativas para compreender o mundo.

Havia quatro assuntos que os antigos Gregos consideravam fundamentais: a aritmética, a geometria, a astronomia e a música. Descobriram também que os princípios astronómicos podiam ser descritos em termos de conceitos geométricos e os princípios musicais em termos de ideias matemáticas. Ficam então dois assuntos fundamentais: os números e a geometria.

Mas os Gregos haviam estabelecido também uma ligação entre os números e a geometria, precisando, que um número é o comprimento de um segmento. Esta ligação foi subsequentemente destruída pela descoberta, no século $\mathrm{v}$, antes de Cristo, de que $\sqrt{2}$ era incomensurável, isto é, não podia ser expresso como a razão de dois inteiros. Foi apenas, basicamente, reestabelecida no século XVII com a descoberta das coordenadas geométricas por Fermat e Descartes.

Os antigos Gregos puseram-nos no longo caminho que vai do terror e da inexplicabilidade constantes à idade cientifica moderna, onde temos conseguido uma compreensão extraordinária dos fenómenos físicos e biológicos. O primeiro passo brilhante neste caminho foi, simplesmente, a hipótese de que o mundo era racional e «podia» ser compreendido e, mais, podia ser compreendido através da linguagem da matemática; isto é, pelos números e pela geometria. Platão afirmava que as leis matemáticas, eternas e invariáveis, são a essência da realidade e que a realidade objectiva e universalmente válida pertence apenas ao campo das ideias. Do ponto de vista do século XX podemos apenas maravilhar-nos com a audácia deste ponto de vista.

Os Gregos estudaram figuras geométricas planas bem como curvas (a circunferência, a elipse, a parábola e a hipérbole; isto é, as secções cónicas) e as superficies obtidas pela rotação destas curvas em torno de um eixo central. Imaginaram circunferências a rolar em circunferências, que por sua vez podiam rolar noutras circunferências, criando assim classes de curvas inteiramente novas.

Os cientistas da Antiguidade usaram estas curvas para criarem um modelo matemático do movimento dos planetas e das estrelas no céu. Pitágoras supunha que as estrelas estayam ligadas a uma esfera de cristal que rodava diariamente em torno de um eixo passando pela Terra. 
Analogamente, os outros sete corpos celestes antigos - o Sol, a Lua, Mercúrio, Marte, Júpiter, Vénus e Saturno - estavam cada um deles ligados a uma esfera móvel própria.

Mais tarde, Platão, no seu Timeu, ligou a criação do tempo à do céu e dos planetas. O Sol, no seu curso, define o dia e a noite bem como o ano, enquanto a Lua descreve o mês quando, na sua órbita circular, ultrapassa o Sol outra vez, «e os ciclos dos outros planetas os homens não os compreenderam, excepto alguns entre muitos, e não deram nem nomes a estes ciclos, nem mediram as suas órbitas usando números, fazendo observações, de modo que não sabem verdadeiramente que a diversidade intrincada e a alteração maravilhosa do vaguear daqueles planetas é tempo também». O conceito pitagórico dos planetas e dos céus tornou-se mais tarde uma teoria do movimento dos corpos celestes, que formou a base da astronomia até ao século XVı. O que aconteceu foi o seguinte:

As secções cónicas foram estudadas durante muitos anos, mas os resultados principais foram obtidos por Apolónio de Perga (262 a.C. 190 a.C.). São descritos nos seus oito livros, Secções Cónicas, dos quais os primeiros quatro são revisões do trabalho feito por Euclides, trabalho que posteriormente se perdeu para sempre. Também o oitavo livro do tratado de Apolónio parece ter-se perdido.

A descoberta das secções cónicas é atribuída a Menecmo, membro da escola de matemática de Platão. Esta escola floresceu na cidade-estado de Atenas no século IV, logo a seguir ao século de Péricles, o periodo clássico da arte, arquitectura e filosofia gregas, em que foi construída a Acrópole.

Platão, um estudante de Sócrates, fundou a sua escola, a Academia, numa zona sagrada de Atenas chamada Akademeia (em honra do herói Akademos). O nome de todas as academias posteriores derivou do nome desta instituição, que existiu ininterruptamente durante cerca de um milhar de anos, até ser dissolvida pelo imperador Justiniano, em 529 d.C. A escola de Platão era como uma pequena universidade onde o filósofo e os amigos leccionavam. Dois dos grandes matemáticos da antiguidade, Eudoxo de Cnidos (408 a.C. -355 a.C.) e Teeteto (420 a.C. -367 a.C.), foram membros da Academia. Embora Platão não fosse um matemático, apreciava tanto esta ciência que exigia que cada estudante dedicasse dez anos às ciências matemáticas e mais cinco à filosofia. A inscrição à entrada da Academia diria "Que não entre aqui ninguém que não seja familiar com a geometria».

Conta-se que Platão sugeriu o seguinte problema aos seus estudantes: explicar o movimento dos corpos celestes combinando vários movimentos 
circulares e esféricos. Platão não apreciava especialmente a astronomia como ciência prática, igualmente útil para os lavradores e para os homens do mar. Na sua opinião, só merecia atenção como recreio para os géometras, para quem era uma fonte de problemas interessantes.

Que problemas apresentavam os movimentos dos planetas? Observados da Terra, estes movimentos parecem muito complicados. Os movimentos do Sol e da Lua podem ser grosseiramente descritos como circulares e de velocidade constante, mas os desvios da órbita circular eram uma fonte de problemas para os Gregos, que se sentiram desafiados a encontrar algumas explicações para aquelas irregularidades. As órbitas observadas dos planetas são ainda mais complicadas porque, à medida que os planetas fazem uma revolução, invertem o sentido por algum tempo, voltam a invertê-lo para avançar, tudo com velocidade variável. Os Gregos procuraram compreender este movimento aparentemente descontrolado por meio de um modelo geométrico.

Eudoxo estudou o problema e propôs uma teoria elegante e puramente geómétrica dos movimentos celestes, que, contudo, tinha o defeito grave de não explicar muitos dos dados empíricos. Assim, no século III a.C., Apolónio de Perga sugeriu que as órbitas celestes deviam ser explicadas pela combinação de movimentos circulares. Nasceu assim a teoria astronómica mais importante dos dois milénios seguintes. Foi desenvolvida detalhadamente por Hiparco, o maior astrónomo da Antiguidade, no século II, a.C. O seu trabalho chegou até nós através da célebre Colecção Matemática, escrita pelo astrónomo grego Ptolomeu de Alexandria, no século II d.C., e chamada al-magest, «a maior», pelos astrónomos do mundo árabe da Idade Média. Este livro completou o sistema geocêntrico da astronomia, conhecido mais tarde por sistema ptolomaico. A teoria de Ptolomeu foi tão bem aceite que na Idade Média se pensava que havia sido dada directamente por Deus ao homem. Todos estes resultados confirmaram o ponto de vista platónico da concepção matemática do universo e estabeleceram a sua ligação ao Criador.

Antes da era grega, eram os deuses que eram responsável pelas atribulações dos homens, não sendo assim surpreendente que, com a ascensão da interpretação racionalista da natureza e com o êxito na descrição matemática da mesma natureza, Deus tenha sido ligado à matemática,

Já em 100 d.C., Nicómaco escreveu: «A aritmética é a mãe de tudo o mais, existindo naturalmente antes do começo, no espírito do Deus criador. Faz parte da concepção universal e extraordinária que o Criador do universo iniciou». 
Os Gregos puseram, outras questões fundamentais relativas ao mundo em seu redor e em alguns casos respondera-lhes. Afirmaram que a luz viajava com velocidade finita e em linha recta. Compreenderam a lei da reflexão da luz e perceberam que esta lei era uma consequência de uma lei mais fundamental ainda: que a luz segue o caminho mais curto.

Puseram questões acerca de formas matemáticas ideais e pensaram nas suas ligações com o mundo natural. Platão previu o desenvolvimento da física moderna, porque compreendeu que o mundo objectivo só podia ser interpretado, ou mesmo compreendido, através de uma lente matemática. $\mathrm{Na}$ sua busca de formas ideais, classificaram os cinco poliedros regulares: cubo, tetraedro, octaedro, icosaedro e dodecaedro.

Seguindo a linha de pensamento originada no princípio mínimo que descreve os raios luminosos, Pappus interrogou-se sobre se as abelhas construíam os seus favos de modo a usarem a menor quantidade de cera, uma questão que não foi respondida até à segunda metade do século Xx.

Os Gregos antigos foram também os primeiros a aplicar a matemática na guerra e a tornar possível o uso moderno da matemática, tanto na guerra como nos serviços secretos. Desenvolveram o conceito de código para a entrega de mensagens secretas entre governos e comandantes no campo de batalha. Na verdade, a maior razão da fama de Arquimedes foi a defesa notável da cidade de Siracusa contra os Romanos, em 214 d.C., durante a segunda das três Guerras Púnicas. Chegou até nós a seguinte descrição da batalha:

Quando os Romanos cercaram a cidade depararam com um inimigo a quem o matemático de 73 anos havia fornecido armas inesperadas e poderosas. As legiões romanas, ao aproximarem-se, foram desbaratadas por uma artilharia muito eficaz, que disparava mísseis de pedra de longo alcance, e por uma quantidade enorme de projécteis de curto alcance. Os barcos da frota romana foram afundados por guindastes enormes, que ou deixavam cair pedras sobre eles ou levantavam as proas com uma garra de ferro e subitamente os esmagavam contra a água. Plutarco (na sua Vida de Marcelo) relata como o comandante Marcelo se dirigiu ao seu exército:

Não vamos pôr fim à luta contra este Briareus geométrico [um gigante de cem braços de lenda grega] que usa os nossos barcos para tirar água do mar, que infamemente fustigou e obrigou à retirada da sambuca [a escada de assalto romana, usada para escalar as muralhas de uma cidade cercada] e que pela quantidade de mísseis que nos atira ao mesmo tempo supera os gigantes de cem braços da mitologia? 
Os soldados romanos estavam aterrorizados. Diz Plutarco,

Bastava que vissem uma corda ou um pedaço de madeira estendendo-se para além das muralhas para fugirem, exclamando que Arquimedes tinha mais uma vez inventado uma nova máquina para os destruir.

Mas para os soldados romanos o pior ainda estava para vir: a redução a cinzas dos seus barcos pelos "espelhos incendiários» de Arquimedes. Em 1200 o historiador bizantino Tzetzes, infelizmente um escritor não particularmente digno de crédito, fez o seguinte relato do que Arquimedes teria conseguido:

Quando os barcos romanos estavam ao alcance do tiro da proa, Arquimedes fez uma espécie de espelho hexagonal, e outros pequenos com 24 lados, que colocou a uma distância apropriada e que ele podia mover com a ajuda de dobradiças e fios de metal. Dispôs o espelho hexagonal de modo a ser bissectado pelo meridiano do Inverno e do Verão e os raios solares recebidos por este espelho, depois de reflectidos, provocaram um grande incêndio que reduziu os barcos romanos a cinzas, ainda que se afastassem do alcance da proa.

Um tal conjunto de pratos reflectores podia ter criado o mesmo efeito que um espelho parabólico.

O cerco de Siracusa durou dois anos e a cidade caiu por traição. A seguir ao assalto, o velho cientista foi morto violentamente por um soldado romano, embora o comandante Marcelo tivesse pedido aos seus homens que poupassem a vida de Arquimedes. Diz a lenda que Arquimedes estava sentado à frente da sua casa a estudar algumas figuras geométricas desenhadas na areia. Quando um soldado romano se aproximou, Arquimedes gritou: «Não mexa nas minhas figuras». Sentindo-se insultado, o soldado matou o grande homem.

Como por compensação, Marcelo erigiu um túmulo a Arquimedes onde estava representada uma esfera circunscrita por um cilindro, simbolizando, de acordo com os desejos de Arquimedes, o seu teorema favorito sobre os volumes do cone, cilindro e esfera. Quando Cícero (100 a.C. -43 a.C.) visitou a Sicília, conseguiu localizar o monumento coberto de arbustos e espinhos. 
Aparentemente Arquimedes considerava as suas contribuições para a engenharia como feitos menores, que não valeria a pena lembrar mais tarde. Segundo Plutarco,

Ele não se preocupou em deixar qualquer trabalho escrito sobre tais assuntos; para ele a construção de instrumentos era uma coisa sórdida e ignóbil, mais geralmente, qualquer arte dirigida para a utilização e o lucro, e só se empenhava naquelas cóisas que, pela sua beleza e excelência, estão para além das necessidades habituais da vida.

Embora ocupado com a arte de fazer a guerra, como Leonardo da Vinci dois milénios mais tarde, o verdadeiro compromisso de Arquimedes, como o de muitos matemáticos depois dele, era com a beleza e o prazer que fluem do estudo da mais pura de todas as formas de arte, a matemática.

Depois da queda da cidade-estado de Atenas, em 338 a.C., a cidade de Alexandria na foz do Nilo tornou-se o centro da cultura grega, até ser destruída um milénio mais tarde. Por volta de 285 a.C., foi fundado o Museu (ou Templo das Musas), Era uma instituição cultural onde os estudiosos podiam trabalhar e estudar. No seu momento mais alto, a Biblioteca do Museu conteria 750000 manuscritos. Foi em Alexandria que Euclides escreveu os seus Elementos (de matemática), que viriam a tornar-se o livro mais divulgado no mundo ocidental.

A ascensão do cristianismo trouxe maus ventos à cultura grega. Em 392, o imperador romano Teodósio ordenou a destruição dos templos gregos. Hipácia, uma conhecida matemática de Alexandria, recusou renunciar à sua fé grega, foi capturada por fanáticos e morta. Ao mesmo tempo, os livros gregos foram queimados aos milhares. $\mathrm{O}$ golpe final para Alexandria e a ciência grega veio com a conquista do Egipto pelos muçulmanos, em 640 d.C.. Os livros que restavam foram destruídos.

A maioria dos estudiosos fugiu para Constantinopla, levando consigo vários manuscritos gregos clássicos. Embora năo houvesse ciência ou matemática activas na nova cidade, pelo menos algum do saber clássico foi preservado. A ciência grega tinha sido completamente destruída, mas uma boa parte do seu saber e da sua visão do mundo esperou calmamente em Constantinopla para ser descoberta uns oito séculos mais tarde.

Não quer dizer que todo o saber tenha desaparecido do mundo árabe. Em 830 o astrónomo Mohammed ibn Musa al-Khowarizmi baseou-se nos Gregos, hindus e Babilónios para escrever um tratado clássico, Al-jabr W'al Muqâbala, dando assim a palavra Al-jabr (álgebra), significando restabelecer. Este trabalho resumia o que na altura se sabia sobre equações. 
$\mathrm{O}$ alvorecer da era moderna não começou até à chegada de Ricardo, Coração de Leão, às muralhas de Jerusalém. $\mathrm{O}$ conhecimento grego foi gradualmente trazido para a Europa e absorvido. Com ele veio a profunda e extremamente interessante perspectiva filosófica de que o universo foi concebido matematicamente. Apesar de sinais de que podia realmente ser assim, entrava em conflito com os ensinamentos da Igreja, nomeadamente que Deus concebeu o universo.

A resolução óbvia foi inferir que Deus usou matemática na concepção do universo ou que Deus é um matemático. Por pretensioso que possa parecer, tem sido um princípio que guiou muitos cientistas através dos séculos. Mais, aceitando esta premissa pode inferir-se que, descobrindo as Suas leis matemáticas, se O descobre, ao nosso Criador.

$\dot{E}$ surpreendente talvez para alguns que esta perspectiva tenha vingado como vingou e, mais surpreendente ainda, que sobreviva até aos dias de hoje. Quando Kepler, em 1619, descobriu as suas três belas leis do movimento em termos das secções cónicas gregas, escreveu na sua Harmonia do Mundo:

A sabedoria do Senhor é infinita; são-no também a Sua glória e o Seu poder. Vós, céus, cantai os Seus louvores! Sol, Lua e planetas, glorifiquem-n'O na vossa linguagem inefável! Harmonias celestiais, vós todas que compreendeis os Seus trabalhos maravilhosos, louvai-O. E tu, minha alma, louva o teu Criador! É por Ele e n'Ele que tudo existe. O que conhecemos melhor está n'Ele, bem como na nossa ciência vã. Louvor, honra e glória, a Ele por toda a eternidade.

$\mathrm{Na}$ segunda parte deste século, o prémio Nobel da física Paul Dirac expressou, da forma seguinte, esta opinião.

Parece ser uma das características fundamentais da natureza que as leis fisicas fundamentais sejam descritas em termos de uma teoria matemática de grande beleza e poder, necessitando-se de matemática de alto nível para a compreender. Pode perguntar-se: porque está a natureza construida segundo estas linhas? Pode apenas responder-se que o nosso conhecimento actual parece mostrar que a natureza é constituída assim. Temos simplesmente de o aceitar. Podia talvez descrever-se a situação dizendo que Deus é um matemático de grande categoria e que usou matemática muito avançada nà construção do universo. 
As nossas fracas tentativas matemáticas permitem-nos compreender um pouco do universo $\mathrm{e}$, à medida que formos desenvolvendo matemática cada vez mais avançada, podemos esperar compreendê-lo melhor.

Assim, se há Deus, o matemático supremo, talvez haja uma lei matemática universal da qual tudo o mais decorre.

A primeira pedra filosófica e matemática de uma tal lei foi lançada por Gottfried Wilhelm Leibniz, diplomata, filósofo, matemático, cientista e estudioso universal. As suas ideias filosóficas foram apresentadas no seu Essais de Théodicée sur la Bonté de Dieu, la Liberté de l'Homme et l'Origine du Mal, que apareceu em 1710. Nele desenvolve a ideia filosófica de que o nosso mundo está organizado para ser o melhor mundo possivel. Esta fillosofia, bem conhecida em círculos eruditos na primeira metade do século XVIII, tinha muitos apoiantes. O mais influente era provavelmente o filósofo alemão Christian Wolff (1679-1754). Leibniz. considerou a questão de como a hipótese de um Criador todo-poderoso, omnisciente e infinitamente bom podia ser compatível com as imperfeições da Sua criação.

Simplificando muito, a teoria de Leibniz sustentava que Deus não interfere, como um relojoeiro desastrado, de tempos a tempos com as questões do mundo para regular os ponteiros do Seu relógio. Pelo contrário, Deus criou o Seu mundo numa harmonia pré-estabelecida. Como um relojoeiro habilidoso cuidando do seu relógio, Deus fez a natureza de cada coísa concordar com a natureza de todas as outras por toda a eternidade; portanto, todas as partes estão em completa harmonia com cada uma para sempre. Isto, apenas, é digno de Deus, o ser mais inteligente, e todo-poderoso.

E Deus existe, segundo Leibniz, pela razão seguinte: Deus é o ser que possui todas as propriedades em grau mais elevado, tanto quanto estas propriedades possam coexistir. Esta condição é necessária porque algumas propriedades, como a santidade e a omnipotência, não podem coexistir completamente. A santidade de Deus restringe a Sua omnipotência, uma vez que é incompatível com a Sua santidade fazer o mal que Ele podia fazer sendo omnipotente.

Segue-se pois que Deus pode, na verdade, pensar em todos os mundos possíveis, mas pode querer, e portanto pode criar, só o melhor de entre eles; o melhor mundo possível.

Portanto, a existência deste mundo como o melhor possível é uma consequência da existência de Deus. Assim, qualquer outro mundo seria necessariamente menos completo que o nosso; contudo, a existência de 
muitos males e desigualdades não é negada: o pecado e o mal existem. Mais, Leibniz prova que um mundo sem pecado e sem mal seria impossível.

Matematicamente, Leibniz diz que Deus usa princípios de optimização na concepção do mundo, dos quais o princípio grego de que a luz segue o trajecto mais curto seria um exemplo. Contudo, não foi proposto nenhum princípio geral abrangendo todos os fenómenos até 1744, quando o cientista francês Pierre-Louis Moreau de Maupertuis propôs o seu grande plano do universo, que se tornou conhecido como a lei da menor acção. Maupertuis publicou uma versão elaborada das suas ideias em 1746, «As Leis do Movimento e do Repouso Deduzidas de um Princípio Metafísico». O «principio metafísico" de Maupertuis é a suposição de que a natureza funciona sempre com a maior economia possivel.

Maupertuis definiu o conceito de acção como a energia a actuar sobre o tempo ou, formalmente,

$$
\text { Acção }=\text { Energia } \times \text { Tempo }
$$

Na verdade, esta mesma definição de acção foi tirada de uma das cartas de Leibniz. Muito provavelmente Maupertuis soube deste principio por um membro da grande família Bernoulli, uma dinastia de matemáticos suíços que, a partir de 1690 , faz da cidade de Basileia um centro de matemática mundial.

Maupertuis formulou entào o seu princípio metafísico como $« \mathrm{~A}$ Natureza minimiza sempre a Acção», Maupertuis viu neste princípio uma expressão da sabedoria do Ser Supremo, de Deus, de acordo com a qual tudo na natureza é executado do modo mais económico possível. Escreveu:

Que satisfação para o espírito humano, ao contemplar estas leis que contêm o princípio do movimento e do repouso para todos os corpos no universo, encontrar a prova da existência d'Aquele que governa o mundo.

Desde a descoberta por Marpertuis do seu princípio, tem-se visto que ele é uma lei básica por detrás de todas as teorias fisicas modernas, da mecânica newtoniana ás equações de Maxwell do electromagnetismo, da relatividade geral à mecânica quântica e mesmo à física das cordas, que procura explicar o Big Bang e o começo do tempo.

Contudo, a ideia de uma razão previdente e a compreensão do Criador através das suas leis (matemáticas) perderam importância com a aceleração do progresso científico. Mesmo assim, alguns cientistas modernos ainda sustentaram estes pontos de vista. Entre eles, neste século, o mais proeminente foi Max Planck, o pai da revolução quântica. 
No «dia de Leibniz», 29 de Junho de 1922, Max Planck falou na Academia das Ciẻncias de Berlim e fez as observações seguintes sobre a filosofia de Leibniz e o princípio da menor acção.

... A Teodiceia ... culmina com a afirmação de que o que quer que ocorra no nosso mundo, grande ou pequeno, na natureza ou na vida espiritual, é definitivamente regulado pela razão divina, e de tal forma que o nosso mundo é o melhor mundo possivel.

Manteria Leibniz esta afirmação hoje em dia, tendo em conta a miséria dos tempos actuais, o falhanço amargo de muitos esforços não dirigidos de forma imediata para o ganho material, o facto inegável de a imaginada harmonia geral entre as pessoas estar hoje mais longe da sua concretização do que nunca? Sem dúvida a nossa resposta a esta pergunta teria de ser afirmativa, mesmo se não soubéssemos que Leibniz nunca deixou de se ocupar intensamente até aos seus últimos anos, apesar de um destino adverso e de muitos desapontamentos de todo o tipo, e não erraremos muito se admitirmos que foi exactamente a Teodiceia que o apoiou e confortou nos dias de maior sofrimento da sua vida. Mais uma vez, este é um exemplo comovente da velha verdade de que os nossos princípios mais profundos e sagrados estão firmemente enraizados na nossa alma, não dependendo das experiências no mundo exterior.

A ciência moderna, em particular sob a influência do desenvolvimento da noção de casualidade, afastou-se do ponto de vista teleológico de Leibniz. A ciência abandonou a hipótese de uma razão previdente, especial, e considera cada acontecimento no mundo natural e no espiritual, pelo menos em princípio, como redutível a estados anteriores. Observamos contudo um facto, em especial na ciência mais exacta, que, neste contexto, pelo menos, é surpreendente. A física de hoje, quanto à sua organização teórica, é completamente governada por um sistema de equações diferenciais espaço-tempo que expressam que cada processo na natureza é totalmente determinado pelos acontecimentos que ocorrem na sua vizinhança temporal e espacial imediata. Todo este rico sistema de equações diferenciais, embora difiram no pormenor, pois referem-se a processos mecânicos, eléctricos, magnéticos e térmicos, está hoje inteiramente 
contido num único teorema, no princípio da menor aç̧ão. Abreviadamente, este diz que, de todos os processos possíveis, os que de facto ocorrem são os que envolvem um dispêndio mínimo de acção. Como podemos ver, é necessário apenas um pequeno passo para reconhecer na preferência pela menor quantidade de acção a intervenção da razão divina e descobrir portanto uma parte da ordenação teleológica de Leibniz do universo. A diferença de ponto de vista não é, como vemos, de modo nenhum uma diferença essencial, mas apenas uma diferença de interpretação, uma vez que o primeiro se restringe ao muito pequeno, enquanto o outro abrange grandes distâncias no espaço e no tempo. Todos têm de decidir por si qual o ponto de vista básico e perguntar-se que abordagem acabará por ter mais êxito.

$\mathrm{Na}$ física de hoje, o princípio da menor acção tem um papel relativamente menor. Não se enquadra completamente no quadro das teorias actuais. Claro que é um enunciado correcto; contudo, habitualmente, não serve como fundamento da teoria mas como um apêndice, verdadeiro mas dispensável, porque a física teórica de hoje está feita inteiramente à medida do princípio dos efeitos locais infinitesimais e considera as extensões a espaços e tempos maiores como uma complicação desnecessária e não económica do método de tratamento.

Portanto a física inclina-se para considerar o princípio da menor acção mais como uma curiosidade acidental e formal do que como um pilar do conhecimento físico.

Assim, foi ainda mais surpreendente que tenha sido descoberto que este princípio, originalmente considerado por Leibniz e Maupertuis como um teorema mecânico, era verdadeiro, sem qualquer restrição, para toda a física do seu tempo, por Hermann von Helmholtz. Recentemente, David Hilbert, usando a versão de Hamilton do teorema, estabeleceu-o na teoria da relatividade geral de Einstein. Quanto mais complicadas se tornam as circunstâncias, menos provável é que o domínio de uma tal abordagem seja incompleto por não poder explicar uma relação geral, simples e geralmente aceite. $\mathrm{O}$ nosso desejo de compreensão só será satisfeito se toda a lei, que tenha sido descoberto ser verdadeira, tiver sido compreendida nos seus significado e relevância e integrada na estrutura teórica global. 
Numa conferência num dia de Leibniz posterior, 27 de Junho de 1935 , Planck voltou a reflectir sobre a frase principal de Teodiceia, afirmando que, entre os mundos possiveis, o nosso é o melhor.

Hoje, quando parece ser cada vez mais dificil encontrar um sentido razoável para o desenvolvimento da humanidade, esta frase pode parecer grotesca na sua audácia. Mantê-la-ia Leibniz face aos acontecimentos presentes, aos erros da Grande Guerra, à desconfiança mútua generalizada e ao armamento crescente dos povos? Teríamos de responder afirmativamente a esta pergunta, mesmo se não soubéssemos que Leibniz não abandonou a sua filosofia por causa dos horrores da Guerra dos Trinta Anos, que atingiu os seus dois primeiros anos de vida, nem pela profunda e sub-sequente humilhação do seu país. Mais precisamente, é um facto que a filosofia da Teodiceía não pode ser provada nem negada pela história. Não é resultado da experiência, mas a suposição e o ponto de partida da atitude de Leibniz perante o mundo. Segundo o seu ponto de vista filosófico, qualquer contradição aparente, cada sofrimento, cada injustiça no mundo podem ser justificados pelo facto dé a limitada mente humana ser incapaz de reconhecer a ligação completa de um acontecimento com a concepção global da criação. Da mesma forma que pela destruição de uma parte, o todo pode avançár, assim um mal local pode ajudar a melhorar e a aperfeiçoar o geral.

Recorde-se que o filho mais velho de Planck, Karl, foi morto em Verdun em 1916; ambas as filhas morreram ao dar à luz os seus primeiros filhos; o filho mais novo, Erwin, foi condenado à morte pelo juiz Freisler, de Hitler, e executado em Janeiro de 1945, pelo seu envolvimento na tentativa de assassinato von Stauffenberg. Pouco depois, Planck perdeu todos os seus haveres pessoais e, com quase 87 anos de idade, fez parte da grande migração de refugiados para o Ocidente, como milhões de outros antes e depois dele 2 .

Universidade da Califórnia

Santa Cruz

2 Para uma descrição mais pormenorizada do princípio da menor acção, ver The Parsimonious Universe, de Stefan Hildebrandt e Anthony Tromba, SpringerVerlag, Nova Iorque (1996). 
Nota do Tradutor: Algumas pessoas concederam-me um pouco do seu tempo e apresentaram-me sugestões sobre a tradução de algumas passagens do texto original. Seguidas ou não, todas se revelaram úteis e justificam o meu agradecimento, que vai para os professores Onésimo Teotónio Almeida, José Ribeiro Ferreira, J. A. Sampaio Martins, Manuel Portela e, em especial, Alan Freeland. 
(Página deixada propositadamente em branco) 


\section{$\begin{array}{llllll}\text { C I E } & \mathbf{N} & \mathbf{C} & \mathbf{A}\end{array}$}

mitiram realizar com sucesso tarefas tão distintas como a programação de um voo a Marte, a previsão de resultados eleitorais, a explicação do funcionamento de alguns mecanismos do sistema nervoso, ou a abordagem critica de obras de arte e de textos literários. Da ciência à sociedade, dos grandes avanços técnicos à solidez de uma argumentação lógica, a Matemática constrói teias de uma imensa flexibilidade resultante do carácter universal da sua linguagem.

Neste livro, personalidades de diferentes universos dão o seu testemunho sobre a forma como usam as teias matemáticas para tecer a sua própria visão do mundo.

Maria Paula Serra de Oliveira é professora de Matemática na Faculdade de Ciências e Tecnologia da Universidade de Coimbra. 